\title{
AN EVALUATION OF ENTERPRISE MODELLING METHODS IN THE LIGHT OF BUSINESS AND IT ALIGNMENT
}

\author{
Banafsheh Khademhosseinieh and Ulf Seigerroth \\ School of Engineering, Jönköping University P.O. Box 1026, SE-551 11, Jönköping, Sweden \\ \{Banafsheh.Khadem,Ulf.Seigerroth\}@jth.hj.se
}

Keywords: Enterprise modelling, IT alignment.

Abstract: $\quad$ All organisations have to keep improving different aspects of their business in order to survive in their business area. This improvement can be done in different ways, including as business and IT alignment. There exist different ways of performing business and IT alignment, such as applying EMMs. Enterprise Modelling (EM) is an area that has been built up with the intention of improving business practice and management. An Enterprise Modelling Method (EMM) is a systematic way of building models that are to be used for planning improvements. For this purpose, it is needed to make an evaluation of methods capabilities in supporting business and IT alignment. According to all above, the results of this paper include a list of EMMs that are applicable in business and IT alignment.

\section{INTRODUCTION}

According to (Harmon, 2010), EM and Business Process Management (BPM) are two areas that for a long time have been part of a tradition where the mission is to improve business practice and management. In this tradition the process is usually manifested through the action of taking a business from one state into another improved state, i.e. a transformation of the enterprise into something that is regarded as better. A challenge that is expressed for BPM is that we need to move beyond a narrow focus on one tradition or technology and actually deal with a number of conceptual ways to slice the business in an integrated way (ibid). Slicing a business (or in a more general form, an enterprise) means assuming some logical and virtual border-lines between its different parts with the purpose to ease the analysis. The same argumentation can be found in the area of EM and Enterprise Architetcture (EA), where there is a need to conceptually slice the business but these slices must be treated as parts in some total alignment context and relate to each other, as it is stated by (Lankhorst, 2005). In order to conduct enterprise modelling to produce different models we often seek support in methods to guide our actions. Methods usually provide a notation language with rules for representing these conceptual slices (models) of the enterprise.

As it is expressed by ()WegmannLRW07, it is necessary to apply an IT system that aligns to the business goals of an organisation. Hence, it is needed that people who are involved in this process have solid understanding about what the current state of the IT alignment is and what the desired state will be. In this way, using enterprise models can be considered as a helpful support. In this paper we have the ambition to make an evaluation of different enterprise modelling methods in order to shed some light on their ability to be used as instrumental support for business and IT alignment. To be able to make this evaluation we will use a conceptualisation of methods (a method theory) as a base for classification and evaluating each enterprise modelling methods. This will then be used as a foundation to discuss and to draw conclusions about these methods in terms of their potential in the area of business and IT alignment.

According to all above, we have defined our research questions:

RQ 1. How does application of EMM support business and IT alignment?

RQ 2. What aspects need to be covered by EMM to cope with business and IT alignment?

RQ 3. What roles should be involved in business and IT alignment with the help of EMM?

The remainder of this paper will proceed as follows: In section 2 we discuss the Related Research; this consists of The Notion of Method (2.1), Business and IT Alignment (2.2). In section 3 the applied Research Method is described. This explanation is given by how The Selection of Papers (3.1) and Use of the 
Notion Method (3.2) were performed. Section 4 contains the Results \& Discussion that are gained by conducting this work. The results are on Enterprise Modelling Methods (4.1) and Enterprise Modelling Methods in Business and IT Alignment (4.2).. Section 5, which is the last section in this paper is Conclusions \& Future Work. This will be divided into three subsections, which are Conclusions about Application of Enterprise Modelling Methods in Business and IT Alignment (5.1), Discussion of Research Questions (5.2) and Future Work (5.3).

\section{RELATED RESEARCH}

In this section we present a method theory (The Notion of Method) as well as a theoretical foundation for business and IT alignment.

\subsection{The Notion of Method}

The Notion of Method that is used in this work has been adopted from (Lind et al., 1998). "A method is prescriptive in character since it gives us guidance on what to do in different situations in order to reach certain goals" ()LundqvistHS09. During modelling there is usually a need to document different aspects and many modelling methods therefore include roles for representation, which is often called modelling techniques or Notations. Such methods also provide procedural guidelines (Procedures), which are many times tightly coupled to Notation. The Procedure involves some meta-concepts as process, activity, information, and object. They are also parts of the semantics of the Notation. The Concepts are the cement and the overlapping parts between Procedure and Notation. Methods can thus be crystallised into: Perform action $A$, in order to reach goal $G$.

It has now been stated that Procedure, Notation and Concepts, among other things, constitute methods (ibid). When there is a close link between Procedure, Notation, and Concepts, it is referred to as a Method Component (Röstlinger and Goldkuhl, 1996). (Avison and Fitzgerald, 2006) have shown that a method is often a compound of several Method Components to what many times is called a Methodology, as it is cited in (Lind et al., 1998). These different Method Components together form a structure called a Framework, which includes the phase structure of the method. All methods build on some implicit (tacit) or explicit Perspective. Such a Perspective includes values, principles and categories (with definitions), which are more fully expressed in the method and its Method Components. The Perspective is the conceptual and value ba- sis of the method and its rationality (Lundqvist et al., 2009). In other words, Perspective specifies the viewpoints that should be taken while developing the conceptual slices (models).

As it is stated in (ibid), another aspect of methods is labelled as Co-operation Principles; i.e. how different persons interact and co-operate when performing method guided work. Co-operation Principles have to do with roles and division of work in the process. This aspect is labelled Collection Principles and it is conceptually important to distinguish between a Procedure (What questions to ask?), Co-operation Principles (Who puts/collects questions?) and Collection Principles (How to collect answers?). A Method Component (with procedures) can be used within several different Co-operation Principles forms, as e.g. seminars, brainstorm sessions as againts interviews.

\subsection{Business and IT Alignment}

An organisation needs to take advantages from resources in order to accomplish its duties. "The key question is whether an enterprise's investment in IT is in harmony with its strategic objectives (intent, current strategy and enterprise goals) and thus building the capabilities necessary to deliver business value. This state of harmony is referred to as alignment" (Board Briefing on IT Governance: http://www.isaca.org). Carrying out business and IT alignment helps the stakeholders to ensure that the applied IT structure supports the organisation in achieving its goals, i.e. business and IT alignments has been provided. An EMM helps in building up models that show the current (AS-IS) and future (TO-BE) status of an enterprise. These models will be used in different analysis procedures such as business and IT alignment in an organisation. In fact an EMM can be used to illustrate the relations between the organisation and the IT structures. The strategic alignment model that is used in this paper is the one that developed by (Henderson and Venkatraman, 1993). Based on this alignment model, Business determines Organisational Infrastructure \& Processes that have to be set up in an organisation. This specifies the suitable IS Infrastructure \& Processes that should be selected. Selection of Architecture in $I S$ is a part of decision about the IS Infrastructure \& Processes. Therefore, depending on the selected IT and Business Strategies as well as Organisational Infrastructure \& Processes, the Architecture of IS varies.

Organisational Infrastructure \& Processes and IS Infrastructures \& Processes need to establish their strategies, respectively called IT Strategy and Business Strategy. These two are needed in order to steer 
the procedure of reaching the business goals. From the other side, strategic alignment should exist between Business and Information Technology. In fact, business determines what kind of Information Technology should be applied; the selected Information Technology should support gaining the business goals of the organisation. Although creating alignment between Organisational Infrastructure \& Processes, Business Strategy, IS Infrastructure \& Processes and IT Strategy gives assurance that the business will be running smoothly, it might result in some restrictions.

\section{RESEARCH METHOD}

In this section we present how we have selected the papers that describe methods for enterprise modelling. Moreover, it will be shown how we have made the classification of the enterprise modelling methods based on the earlier presented method theory.

\subsection{Selection of Papers}

The papers that have been used for this work were retrieved by going through different series of conference proceedings. At this step of the work the aim was finding references that were dealing with EMMs and frameworks. Therefore, we carried out the work by checking the acknowledged conferences in this field, as well as other well-known conferences in the field of information systems that cover different research areas. The list of reviewed conferences are listed as below:

- Practices of Enterprise Modelling (PoEM) 20082010

- Exploring Modelling Methods for Systems Analysis and Design (EMMSAD) 2000-2010

- International Conference on Information Systems (ICIS) 2000-2010

- European Conference on Information Systems (ECIS) 2000-2010

- International Conference on Enterprise Information Systems (ICEIS) 2004-2009

- International Conference on Advanced information Systems (CAiSE) 2000-2010

Besides working with the above mentioned conference proceedings, some papers, e.g. (Wang et al., 2009) and (Frank, 2002), were retrieved from other sources, such as journals or conferences that focus on a wide range of fields.

The selection of papers was done by following a straight-forward but useful strategy: as the first step, we went through the key words and looked for the terms Modelling and Enterprise Modelling. In case each of these terms (preferably Enterprise Modelling) existed in keywords, we proceeded to see if the term Method was also presented or not. Usually when both of these terms existed in the keywords, it was a sign that was showing the paper presents a method. As the second step, we read the abstract and summary for each paper. By taking both of these two sections into account, we could decide if the paper has discussed a method or some kind of approach for enterprise modelling. But this is not enough for recognising a method. Some authors do not differentiate between concepts such as method and an approach and use these terms instead of each other. Therefore, as the next step we had to go through the main body of each paper to see what was really being presented and discussed. This step was done mainly by checking the headings \& sub-headings, figures and tables. In fact, in this step a manual data mining method was used.

This resulted in finding the sections that are more relevant to this work and had to be reviewed. Then the mentioned sections were read. Reading these sections together with assessment of the figures and tables was the last step of this stage.

\subsection{Use of the Notion of Method}

Going through papers that come from different sources provided us with sources for this study. Then, it was needed to perform some kind of filtering in order to check if the selected papers will match our purpose. All works were reconstructed, positioned, and described according to The Notion of Method. Then this was used to evaluate if the selected papers presented a method or some other prescriptive instructions. In order to answer this question, we have applied the conceptual structure in the method notion that was presented in section 2.1 and classified the papers based on The Notion of Method. This means that the descriptions of the method or approach for enterprise modelling in the paper were assessed based on the presented Notion of Method. The most important part of The Notion of Method that had to be covered (to conclude that the paper is presenting a method) was Method Component.

\section{RESULTS \& DISCUSSION}

In this section we will discuss which EMMs can serve as a support for the purpose of business and IT alignment. 
Table 1: Enterprise Modelling Methods for Business and IT Alignment.

\begin{tabular}{|c|c|c|c|c|c|c|c|}
\hline $\begin{array}{c}\text { Method or Framework } \\
\text { Name }\end{array}$ & Perspective & Pr & N & C & MC & F & CCP \\
\hline $\begin{array}{c}\text { ARCHIMATE } \\
\text { (http://archimate.org/ })\end{array}$ & Describing EA & FC & PC & FC & PC & FC & NC \\
\hline $\begin{array}{c}\text { ZACHMAN (Sowa and } \\
\text { Zachman, 1992) }\end{array}$ & Defining a 3-layer EA & FC & PC & FC & PC & PC & NC \\
\hline i*(Yu, 1995) & Early phase requirements engineering & FC & FC & FC & FC & PC & NC \\
\hline $\begin{array}{c}\text { EKD (Bubenko et al., } \\
\text { 2001) }\end{array}$ & $\begin{array}{c}\text { Modelling the current situation of the } \\
\text { enterprise, the change requirements and the } \\
\text { possible alternatives }\end{array}$ & FC & FC & FC & FC & FC & FC \\
\hline $\begin{array}{c}\text { MEMO(Frank, 2002) } \\
\text { knowledgebase }\end{array}$ & $\begin{array}{c}\text { Modelling organisational memory/ corporate } \\
\text { Maiden, 2005) }\end{array}$ & FC & FC & FC & FC & NC & NC \\
\hline $\begin{array}{c}\text { Modelling and analysing stakeholder's } \\
\text { requirements (Requirements engineering) }\end{array}$ & FC & FC & FC & FC & PC & NC \\
\hline $\begin{array}{c}\text { REAM (Wegen) } \\
\text { 2007) }\end{array}$ & $\begin{array}{c}\text { Requirements engineering and organisational } \\
\text { IT alignment }\end{array}$ & FC & FC & FC & FC & FC & NC \\
\hline PRiM (Grau et al., 2008) & $\begin{array}{c}\text { Business process reengineering practice with } \\
\text { the purpose of IS development }\end{array}$ & FC & FC & FC & FC & PC & NC \\
\hline
\end{tabular}

\subsection{Enterprise Modelling in Business and IT Alignment}

Enterprise modelling is not just about drawing models in terms of representations and then leaving them. These models should rather be the basis for practical use in other areas. In order to see if an EMM is applicable in another field, it should be investigated whether the method is able to fulfil the aims of that certain field. When it comes to business and IT alignment, it is needed to explore whether the perspective of the method matches the objective of business and IT alignment. According to (McKeen and Smith, 2003), strategic alignment of IT exists when a business organisations goals and activities are in harmony with the information systems that support them. In other words, any for any organisation, IT requirements should be in alignment with its business strategy (Bleistein et al., 2006). This alignment can be between the IT system and the business use cases or between the IT system and structure of the system. Consequently, methods with Perspectives of modelling an enterprise together with its linkage to the environment (including its IT system) and methods that are developed to be used for requirements engineering are suitable for this purpose. Regarding the latter, the EMM should not be built up for purposes that do not embrace IT system requirements.

As mentioned in section 2.1, a modelling method might cover several aspects of an enterprise. Therefore we needed to find out what aspects of The Notion of Method that have been covered by each method. The result of this assessment were later on used in the next step which was evaluating the EMMs potential in the field of business and IT alignment. The result of this assessment has been shown in Table 1. Using this table, the user has the possibility to pick up an EMM that is applicale for the purpose of business and IT alignment. Even if he/she has needs to work with a method that covers one or more aspects of the the Notion of Method, this table can support this purpose. This table consists of two main sections. The first section shows the name of each method or framework (if any name has been given) in the first column (Method or Framework Name) and the Perspective of the method as the second column. The Perspective of each method is defined with respect to its area of usage and shows in which cases the method can be applied. The second section is called Coverage. It shows if different aspectsof The Notion of Method (Pr (Procedure), $N$ (Notation), C (Concepts), MC (Method Components), $F$ (Framework) and CCP (Cooperation \& Collection Principles)) are Fully Covered (FC), Partially Covered (PC) or Not Covered (NC).

\section{CONCLUSIONS \& FUTURE WORK}

In this section the results that have been achieved during the work are presented. The results are presented in the form of a list. This list contains a number of conclusions about application of enterprise modelling methods for the aim of business and IT alignment. 


\subsection{Conclusions about Application of Enterprise Modelling Methods in Business and IT Alignment}

Below you can find a list of conclusions business and IT alignment and EMMs that are suitable for business and IT alignment:

1. Fulfilling business and IT alignment means providing harmony between Business Strategy, Organisational Infrasructure \& Processes, IT Strategy and IS Infrastructure \& Processes in parallel with their sub-dimensions.

2. To check if an EMM is usable in business and IT alignment, it should be checked if it can support modelling an enterprise, its business and IT system. Too, it should serve elaborating the relation between the enterprise business and its IT system.

\subsection{Discussion of Research Questions}

Checking different sources that represent EMMs and frameworks and then reviewing their potencies in case of application in business and IT alignment, we put the following discussions as the answers of research questions:

RQ 1. How does application of EMM support business and IT alignment?

As mentioned before, the intention of EM filed is making improvements in enterprises. In this way EMMs help in illustrating the current and future state of an enterprise. This illustration will be useful in planning improvements in different aspects of the enterprise, including IT system. An enterprise needs to have an IT system that is in accordance to its business. Checking alignment of IT is vital for guaranteeing that IT system will support the business of the enterprise. A part of this guarantee is keeping the IT system up to the new situation of the enterprise. Using EMMs helps in showing the situation of alignment between the enterprise and its IT system and how it should be in the future state. This is done by drawing the current and future state models, respectively. Then based on the developed models, it can be decided what type of IT system will be useful in the future state. Moreover, it can be determined how to perform changes to move from the current IT system to the desired one. Therefore, it can be said that EMMs are applicable in performing business and IT alignment.

RQ 2. What aspects need to be covered by EMM to cope with business and IT alignment?
For checking alignment between two sections, it is important to know what part of each should be included in the alignment. When it comes to business and IT alignment, one side of alignment is the IT system. On the other side, there is an enterprise. While checking and planning alignment, it is possible to include two aspects of the enterprise in this process. One aspect is the set of business processes of the enterprise and the other one is the environment $\&$ structure of the enterprise. As business and IT alignment is more about checking if an IS fits to the business of an enterprise, synchronisation between the IT system and the business of the enterprise should be investigated and confirmed.

RQ 3. What roles should be involved in business and IT alignment with the help of EMM? For conducting modelling sessions, it is needed to involve people who ask questions and people who answer them. People who ask questions are usually modelling experts and people who answer the questions are the ones who are field experts. Consequently, when modelling is being done in order to provide business and IT alignment, IT experts will be the ones who answer the questions

\subsection{Future Work}

After achieving the above mentioned results, the next step will be performing case studies. This will help in checking to what extent the presented list of EMMs support business and IT alignment.

\section{REFERENCES}

Avison, D. and Fitzgerald, G. (2006). Information Systems Development: Methodologies, Techniques and Tools. McGraw-Hill Higher Education, 4 edition.

Bleistein, S., Cox, K., Verner, J., and Phalp, K. (2006). BSCP: A requirements analysis framework for validating strategic alignment of organizational IT based on strategy, context, and process. Information and Software Technology, 48(9):846-868.

Bubenko, J. j., Persson, A., and Stirna, J. (2001). D3: User guide of the knowledge management approach using enterprise knowledge patterns. Technical report, Royal Institute of Technology (KTH) and Stockholm University, Stockholm, Sweden.

Frank, U. (2002). Multi-perspective enterprise modeling (memo) - conceptual framework and modeling languages. In HICSS, page 72.

Grau, G., Franch, X., and Maiden, N. A. (2008). Prim: An $i^{*}$-based process reengineering method for information systems specification. Information and Software Technology, 50(1-2):76-100. Special issue with two 
special sections. Section 1: Most-cited software engineering articles in 2001. Section 2: Requirement engineering: Foundation for software quality.

Hackett Best Practices (2002). Book of Numbers Information Technology. Hackett Group.

Harmon, P. (2010). The scope and evolution of business process management. In Brocke, J. v. and Rosemann, M., editors, Handbook on Business Process Management 1, International Handbooks Information System, pages 37-81. Springer Berlin Heidelberg.

Henderson, J. C. and Venkatraman, N. (1993). Strategic alignment: Leveraging information technology for transforming organizations. IBM Systems Journal, 32(1):4-16.

Jones, S. and Maiden, P. N. (2005). Rescue: An integrated method for specifying requirements for complex socio- technical systems. In Mate, J. L. and Silva, A., editors, Requirements Engineering for Sociotechnical Systems, pages 245-265. Ideas Group.

Lankhorst, M. (2005). Enterprise Architecture at Work: Modelling, Communication and Analysis. Springer.

Lind, M., Goldkuhl, G., and Seigerroth, U. (1998). Method intergration: the need for a learning perspective. IEE Proceedings - Software, 145(4):113-118.

Luftman, J. and Brier, T. (1999). Achieving and Sustaining Business-IT Alignment. California Management Review, 42(1):109-122.

Lundqvist, M., Holmquist, E., Sandkuhl, K., Seigerroth, U., and Strandesjö, J. (2009). Information demand context modelling for improved information flow: Experiences and practices. In PoEM, pages 8-22.

McKeen, J. D. and Smith, H. A. (2003). Making IT Happen: Critical Issues in IT Management. Wiley, Chichester, Hoboken.

Persson, A. and Stirna, J. (2001). Why enterprise modelling? an explorative study into current practice. In CAiSE, pages 465-468.

Röstlinger, A. and Goldkuhl, G. (1996). Generisk flexibilitet - på väg mot en komponentbaserad metodsyn. Technical Report R-96-15, Linköping University, Linköping, Sweden.

Society, I. C., editor (2008). 41st Hawaii International International Conference on Systems Science (HICSS41 2008), Proceedings, 7-10 January 2008, Waikoloa, Big Island, HI, USA.

Sowa, J. F. and Zachman, J. A. (1992). Extending and formalizing the framework for information systems architecture. IBM Systems Journal, 31(3):590-616.

Wang, H., Wang, G., Wen, X., and Zhou, Y. (2009). An enterprise modelling method based on an extension mechanism. Int. J. Computer Integrated Manufacturing, 22(9):836-846.

Wegmann, A., Lê, L.-S., Regev, G., and Wood, B. (2007). Enterprise modeling using the foundation concepts of the rm-odp iso/itu standard. Inf. Syst. E-Business Management, 5(4):397-413.
Yu, E. (1995). Modelling Strategic Relationships for Process Reengineering. $\mathrm{PhD}$ thesis, Department of Computer Science, University of Toronto, Toronto, Canada.

Zhang, J. (2009). Research on modeling method of virtual enterprise in uncertain environments. In Proceedings of the 2009 International Conference on Computer Engineering and Technology - Volume 01, pages 541-544, Washington, DC, USA. IEEE Computer Society. 